\title{
Adequate Collections in Engineering School Libraries ${ }^{1}$
}

$A^{n}$

RE THERE special problems in considering the needs and desire for maintaining adequate collections in engineering school libraries? Is it necessary to continue to consider these libraries as storehouses of accumulated publications which have been received at some time and added to the collection not always with due consideration of their current value and less as to their continued worth? Rather, can we develop them as a means of communication in which the collections will contain every item needed for the particular purpose of the collection and not a single item which cannot be justified by use?

Adequacy necessarily varies with the individual needs of every institution and is therefore a difficult term to define. Certainly size can no longer be used as a criterion. Blanche Prichard $\mathrm{McCrum}$, in her Standards, offers estimates varying from 35,000 to 150,000 volumes. The North Central Association no longer mentions size but rather submits a representative list for checking. We know, however, that size offers convenient statistics suggesting the resources of the library; that is, you can have a greater expectancy of finding more material on a subject in a collection of 100,000 volumes than in one of 50,000 . $\mathrm{Li}$ braries in the past have doubled in size on an average of sixteen to twenty years, and the date of the statistics given is always important for any comparison. From the

${ }_{1}$ Paper presented at the meeting of the Engineering School Libraries Section, A.C.R.L., Buffalo, June 18 1946. statistics of various reports, this rate of increase seems to be a fact that cannot be overlooked. Do we then want such large collections with their difficulties of use and administration or would it be better for us to hold to smaller, more selective collections which have not only been built up selectively but have been maintained by a planned process of development?

Again, is completeness a fair test of adequacy? This seems to be an impossible goal to attain even in narrow fields of interest and certainly not to be aimed at if we are to cover all the fields of our curricula, because now our concept of completeness is broader and includes not only titles of books with their frequent editions and revisions, but both current and bound files of periodicals and the ever increasing audio-visual aids, photostats, microfilms, recordings, slides, films, etc., and these increase not only in number and in kind but also in demand and must be included in any. attempt at adequacy.

If not size or completeness, selection then would seem to be both the basis and the test of adequacy, and quality rather than quantity the aim. J. Periam Danton shows in his report that libraries maintaining a higher percentage of items in checklists invariably indicate that a greater responsibility for the selection is placed in the librarian. While careful selection necessarily includes a study of the curricula, do the courses stress theory or laboratory, lectures and textbooks or reports? If there is 
provision for graduate work and also the constant changes caused by varying interests of the departments, there is the responsibility of the librarian not only for acquiring but for discarding.

For acquiring new titles and editions there are not only the usual tools of publishers' announcements and catalogs, $P u b$ lishers' Weekly, and Cumulative Book Index, but engineering librarians have such special tools as the Technical Book Review, New Technical Books, the book review columns of various periodicals such as Science and Mechanical Engineering, and the recently published Hawkins' List of Scientific and Technical Books Published in the U.S. between 1930 and 1944. However, it is questionable whether these tools are sufficient for selection since they are used as checklists rather than guides because of the need to supply users with the latest material promptly. Publishers are depended upon for their choice of writers and subjects, and their announcements are the only immediate sources of information concerning the latest books. This would seem to be upheld by recent surveys which show that a lag of at least a year can be expected for a good review of a scientific publication, and there is an even longer delay in the collected lists of reviews.

We constantly hear that scientific and technical books lose their value more quickly than the average publication. Certainly the demand is usually for the latest material. Do our books as a rule lose their value within ten years of publication? If so, is it not more essential for us to weed out our collections more freely, both in number of titles and in time since publication, than in libraries which are predominantly liberal arts? We not only have more editions of a title but more of our titles have several editions than is customary. Do we then need to keep all editions of every title since we have pressure to buy each new edition as soon as it is published? The eight editions of Johnson's Materials of Construction cover a period of 43 years, from 1897 to 1939 . Now, if seven years since the latest edition we feel that it is dated, how much use can we make of the earlier editions except as items of curiosity? This is not an exception. Millard's Physical Chemistry, which has had five editions in twenty years, was issued in its latest edition in 1940, and the chemistry department insists that only the latest be on the shelves for the unwary student.

It is true, as Fremont Rider says, that when we discard we no longer give the use of this material, but is it not possible for librarians to assume greater responsibility for their collections and continue to attempt to keep every item that comes into the library unless it is lost or worn too badly to be rebound? Can we by eliminating, not necessarily the older, but the out-of-date. material, increase the ease of use of our collections and depend upon union catalogs and cooperation to supply this material whose value we now question? If we risk buying unimportant material in our attempt to. supply the latest, we would seem to assume the added responsibility of discarding it to protect the user. This presupposes an ability to select which most of us take for granted but which can be proved only by attracting and satisfying our users and can be obtained only by cooperation with our faculty and students. But the second point is more difficult, that of standing on our own, no longer covered by the tradition that everything once coming into a library must be kept, and justifying our responsibility not only in selecting books but also in discarding them. Development of a satisfactory plan by weeding is therefore an urgent problem needing solution as soon as possible. 